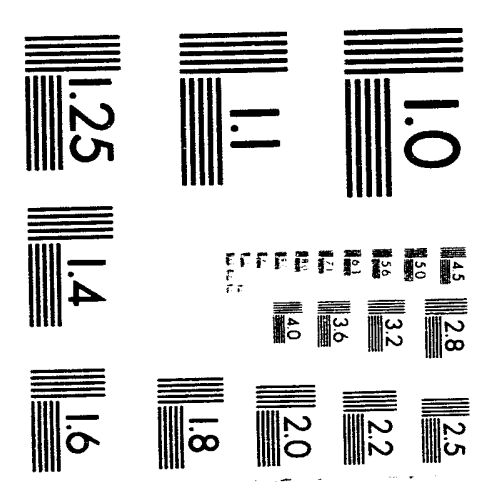



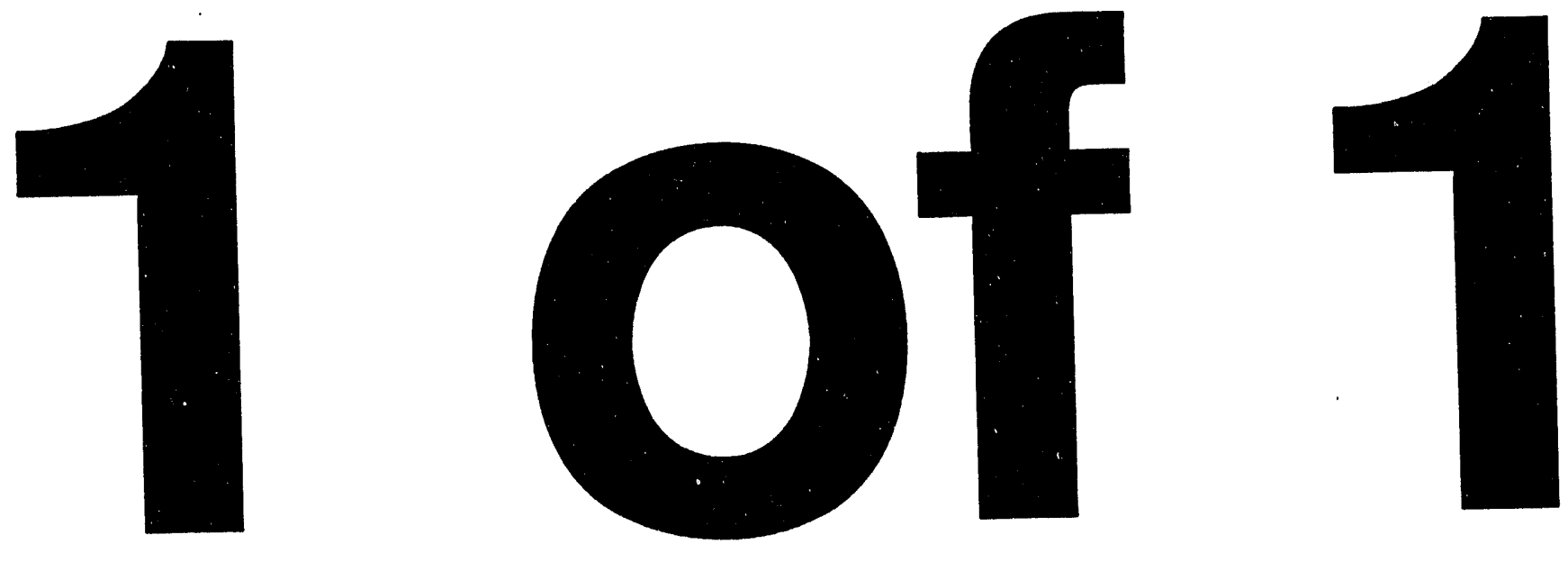


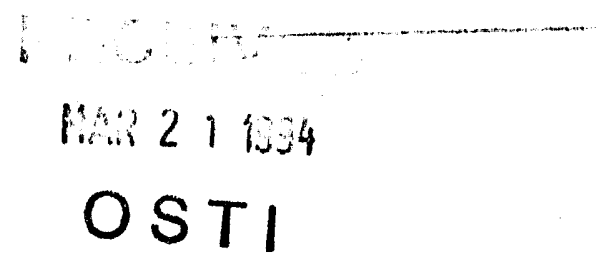

\title{
THE ANALYTICAL FOUNDATIONS OF CONSERVATION POLICY
}

by

\author{
Ronald J. Sutherland
}

October 16, 1992

\author{
Argonne National Laboratory \\ 370 L'Enfant Promenade \\ Suite 702 \\ Washington, DC 20025 \\ phone 202 488-2412 \\ fax $202488-2413$
}

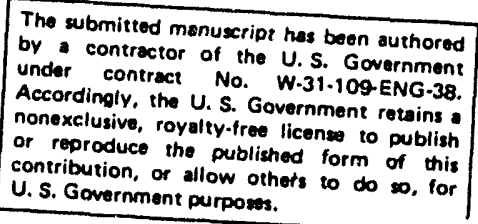

DISCLAIMER

This report was prepared as an account of work sponsored by an agency of the United States Government. Neither the United States Government nor any agency thereof, nor any of their employees, makes any warranty, express or implied, or assumes any legal liability or responsibility for the accuracy, completeness, or usefulness of any information, apparatus, product, or process disclosed, or represents that its use would not infringe privately owned rights. Reference herein to any specific commercial product, process, or service by trade name, trademark, manufacturer, or otherwise does not necessarily constitute or imply its endorsement, recommendation, or favoring by the United States Government or any agency thereof. The views and opinions of authors expressed herein do not necessarily state or reflect those of the United States Government or any agency thereof. 


\section{ABSTRACT \\ THE ANALYTICAL FOUNDATIONS OF CONSERVATION POLICY}

The conservation paradigm is described here as reflecting the policy goal of energy efficiency, the investment model that market barriers inhibit energy efficiency investments and the emphasis of engineering estimates of market efficiency. In contrast, the economics paradigm emphasis economic efficiency and equity, market failures or market imperfections as impediments to achieving economic efficiency and the behavior of markets to make efficient choices. Market barriers discourage investments in energy efficiency, but this is irrelevant for policy purposes where energy efficiency differs from economic efficiency. Where market barriers discourage economically efficient investments, they are of dubious significance for policy purposes unless they are market failures. The market barriers alleged in the conservation literature typically do not coincide with market failures. In a competitive and efficient market economy, investments judged efficient by engineering and present value calculations will not instaneously achieve a market share of 100 percent. Barriers that delay diffusion are not necessarily appropriate for Government policy. 
October 16, 1992

\section{THE ANALYTICAL FOUNDATIONS OF CONSERVATION POLICY ${ }^{\natural}$}

"How beautiful the Emperor's new clothes are!

What a splendid train! And they fit to perfection."

"Nobody would let it appear that he could see nothing..."

... "But he had nothing on!" at last cried all the people.

The Emperor writhered for he knew it was true.

Hans C. Andersen (1984)

\section{INTRODUCTION}

A fundamental proposition of conservation analysis is that market barriers impede cost-effective investments in energy efficiency. In two previous papers on market barriers (Sutherland, 1990, 1991) I concluded that, according to conventional investment analyis, the alleged market barriers do not typically affect investment decisions. Furthermore, market barriers are not market failures and therefore do not produce an inefficient allocation of resources. The implication is that the investment component of the conservation model is without foundation and hence conservation policy recommendations must be viewed with suspicion. My economics colleagues generally viewed the 1991 paper as summarizing widely held views on conservation analysis. However, the conservation community has reacted most unfavorably and has viewed that paper as a challenge and threat to conservation policies. Such a reaction is perhaps warranted.

This paper further develops the analysis of market barriers and market failures and extends the analysis to reflect the different policy objectives of conservationists and economists. The conservationists' response to my assessment of market barriers is expressed by McMahon (1992) and by Sanstad, Koomey and Levine (1992). These authors reflect a perspective developed at Lawrence Berkeley Laboratory (LBL), which has been perhaps the leading research institution in the country in the area of energy efficiency in buildings. These two papers from LBL can be construed as a response from the conservation community. The reassessment and defense of my initial paper is used to develop the main conclusion of this paper - the conservation model is inappropriate for public policy analysis

${ }^{1}$ This paper benefited from the comments by Ken Malloy, Michael York, Sue deWitt and Russ Deiter. The paper is based on research supported by the U.S. Department of Energy, Office of Domestic and International Energy Policy, under contract W-31-109-Eng-38. The views expressed are those of the author and not the Department of Energy. 
because it does not yield policies that enhance the economic well-being of ratepayers and consumers. At stake here is a paradigm for analyzing energy policy issues. The appropriate model for energy policy analysis begins with the policy objectives of economic efficiency and equity and analyzes markets in terms of market failures or imperfections. In contrast, the conservation model emphasizes energy efficiency and the market barriers that discourage adoption of energy efficient technologies or practices.

The contrasting policy goals of conservationists and economists are discussed in Section 2. The policy goals of the economic model are economic efficiency and equity. The policy goals of conservation researchers are saving energy and enhancing energy efficiency. Policies that enhance economic efficiency may increase or decrease energy efficiency, or, their effects may be ambiguous. Policies that enhance energy efficiency may or may not improve economic efficiency. The analysis proceeds in Section 3 by reviewing the alleged market barriers, from an economics perspective. The conclusion is again reached that the alleged market barriers to energy efficiency investments are not consistent with modern investment analysis. Furthermore, these barriers are not market failures and therefore do not restrict the efficiency with which resources are allocated. Section 4 addresses the major market failures in energy markets. Section 5 is a comparison of the conservation and economics paradigms of energy policy analysis. The heart of the economics model is economic efficiency, market failures (or imperfections) and analyzing policy issues in terms of market responses. The conservation model is based on energy efficiency, market barriers and typically engineering estimates of efficiency. Each of the three components of this model - energy efficiency, market barriers and engineering estimates of cost-effectiveness implies that conservation policies are not likely to achieve an efficient allocation of resources.

\section{POLICY GOALS}

\section{Conservation Policy}

My previous paper on market barriers explains that the investment component of the conservation model is not consistent with the standard principles of investment analysis. This paper extents the analysis and shows that the remainder of the conservation model is also inconsistent with basic economics principles. In addition to investment analysis, a second major difference between economists and conservation advocates is the difference in policy goals. The primary economic goal is economic efficiency, although equity is typically considered. Conservation advocates have asserted various goals: energy conservation, reducing energy consumption, improving energy efficiency and undertaking the least-cost use of energy. As depicted in Figure 1, energy efficiency and economic efficiency are different concepts; however, these goals may occasionally coincide. This discussion of energy policy goals suggests that the differences between conservation advocates and most traditional economists may be irreconcilable.

The policy goals advocated by conservationists have evolved over time. Reducing energy consumption was the initial goal of the conservationists. The energy crisis of the 
1970s resulted from a large increase in the world oil price coupled with the voracous appetite for oil products by consumers and businesses. A reasonable solution was to be to reduce energy consumption. The Alliance to Save Energy is a national organization that appears to endorse the goal of reducing energy consumption. The goal of reducing energy consumption has lost broad support over the years because it frequently requires a reduction in our standard of living. For instance, energy consumption in buildings can be reduced simply by turning off the heating and cooling systems, but such a strategy reduces our comfort level and is not widely acceptable. Although reducing energy consumption has support in the conservation community, cost considerations have limited its appeal.

The policy objective that is more widely adopted by conservationists is energy efficiency. Energy efficiency is typically measured as the Btu content per level of output. The energy efficiency of an appliance is the Btu input of energy required to obtain a given level of energy service produced by the appliance. Energy efficiency is enhanced if the appliance can produce the same level of the energy service with fewer Btu of energy input. At the aggregate level, energy efficiency is the Btu input of primary energy used relative to real GNP. The multi-laboratory report to the Department of Energy by Carlsmith et. al. (1990), "Energy Efficiency: How Far Can We Go?", confirms that energy efficiency is the aspired goal. In a further development of this laboratory report, Hirst and Brown (1990) assert this goal in their paper entitled "Closing the efficiency gap: barriers to the efficient use of energy". The thesis in their paper is that "... barriers inhibit the adoption of energyefficient practices and measures." (p. 267). The Hirst and Brown paper appears to reflect a consensus within the conservation community in terms of the policy goal and the importance of market barriers in impeding markets from automatically achieving energy efficiency. The American Council for an Energy Efficient Economy represents the views of conservation advocates and explicitly asserts the policy goal to be energy efficiency. The National Energy Strategy of the U.S. DOE (DOE, 1991) explicitly asserts that energy efficiency, along with economic efficiency, is an energy policy objective.

Energy efficiency is a technical or engineering coefficient and is not measured in monetary units. The input is the level of energy used in the process and output is the level of the energy related service. If energy were measured in dollar costs and output in dollar value, energy efficiency would become an input-output ratio. From an economic perspective, there is nothing inherently efficient about either increasing or decreasing a technical production coefficient, or, an input-output ratio. Economic efficiency is measured in terms of dollar costs and benefits not by technical coefficients of production. If energy efficiency increases, we cannot assume that benefits measured in dollars necessarily exceed costs. Illustrations below involving deregulation and fuel switching will show that economic efficiency may be enhanced when energy efficiency is retarded and when its change is ambiguous. These differences between energy and economic efficiency are reflected in Figure 1 by the area where the two goals do not coincide.

A second limitation of energy efficiency as a policy goal is that it can be achieved 
only by retarding the efficiency of capital or labor. ${ }^{2}$ With the level of energy services held constant, less of one input (energy) can by used only be increasing the level of some other input. Policies that enhance energy efficiency and reduce the efficiency of capital or labor are not unambiguously cost-effective. The mere re-allocation of the share of inputs, such as capital, labor and energy does not enhance economic efficiency. Such policies are implicit in the policy goal of energy efficiency. Given the market prices of capital, labor and energy, there exists an optimum mix of these inputs in a production process. Continuous reductions in the energy-output ratio do not improve productive efficiency.

A third objection to energy efficiency as a policy goal is that it yields no meaningful implications about policies that affect fuel substitution, or the efficiency with which energy is used. Electricity can be produced by several technologies: coal, nuclear, natural gas, hydro and wind, to name only a few. The desirability of substituting one of these fuels for another cannot be determined by the estimated change in energy efficiency as measured by Btu input of primary energy. The optimum mix of technology inputs could be analyzed by a least cost framework, where Btu input would be irrelevant. In terms of Figure 1, the optimum and least cost technology mix is contained in the economic efficiency set and not in the energy efficiency set.

The deregulation of energy markets may contribute to the efficiency with which these markets distribute resources, but the effect on energy efficiency may be ambiguous, or, energy efficiency may be diminished. For instance, the decontrol of wellhead gas prices and the increased access to interstate gas pipelines certainly enhanced the economic efficiency of the gas supply sector. The effect of these decontrols on energy efficiency is ambiguous and immaterial for policy assessment. The potential deregulation of oil pipeline transportation rates may enhance the efficiency of this market. However, deregulation has an ambiguous and irrelevant effect on energy efficiency.

Many economists have been skeptical about the claims and promises from the conservation community. One explanation of this apprehension is that economists do not accept an input-output coefficient as the primary objective of energy policy. Energy efficiency is no more appropriate for energy policy than the initial goal of the conservationists of leaving energy in the ground. A second explanation is that some policies that promote economic efficiency are unrelated to those that attempt to reduce energy consumption.

The goal of energy efficiency is recognized to be devoid of cost considerations and such concerns have resulted in the policy constraint that strategies to attain energy efficiency should be cost-effective. Federal and state policies typically require that energy efficiency

2 In the short run, output can remain constant and one input reduced only be substituting another input. Over time, technical change and education can enhance the productivity of capital and labor thereby producing more output per level of input. 
programs be cost effective, or, be a least cost solution. The least-cost goal differs from energy efficiency in that the goal is measured in dollars rather than as a technical coefficient. In application, this goal appears to be a constraint. Various energy efficiency measures are considered and the cost-effectiveness of the preferred option is then estimated. Conservationists have not generally proposed policy actions that increase energy use and reduce overall costs.

\section{Economic Policy}

In 1776, Adam Smith used the term the "invisible hand" to describe the result that the forces of competition will by themselves result in the most efficient allocation of resources. Economic efficiency means that the maximum value of output is obtained from a given level of inputs. Because economic efficiency is reflected in our overall standard of living, it is generally the accept goal of most economic policy. Certain assumptions about markets are required to obtain this result: a large number of buyers and sellers, free entry and exit, relatively free information, a homogeneous product and no external costs or benefits. Examples of market failures include: external (environmental) costs, barriers to entry or exit, natural monopoly, few buyers or sellers and other imperfections. Policies are typically most effective at achieving competitive results if they focus on market imperfections and attempt to reduce them.

Analyzing conditions of market failure and suggesting policy remedies has been the focus of a large body of economic analysis. Energy issues require application of the same tools used to analyze issues in other markets. The primary policy issue is whether the market in question is perfectly competitive, that is, whether the assumptions of perfect competition tend to hold. If the answer is affirmative, the appropriate policy is to undertake no policy, because the market is achieving optimum results. If a market is not highly competitive, the objective is to identify the source of the imperfection - the market failure and to suggest policies that improve the functioning of the market. In some cases, the cost of economic inefficiency may be less than than the regulatory or other costs of attempting to reduce market failures

The second major concern in economic policy analysis is equity, which reflects the distribution of costs and benefits. Equity includes inter-generational equity as well the distribution of costs and benefits between customer classes, such as industrial, agricultural and residential customers. A serious equity issue arises if energy policies place a heavy burden on low income individuals while benefiting upper income groups. Each of the studies of discount rates on energy efficiency investments reviewed by Train (1985) concluded that low income households have higher discount rates than higher income households. Low income households express a lower value for reducing energy costs than high income households. Energy efficiency standards, which impose a constant discount rate on all consumers, place low income consumers at a relative disadvantage - at least according to their revealed preferences. Such standards are therefore regressive.

The demand side management (DSM) programs being introduced by utilities on a 
wide scale introduce serious equity considerations. In the initial introduction of these programs, a "no losers" test was applied, which is certainly consistent with economic welfare principles. $^{3}$ One of the few DSM programs to meet this test is thermostat adjusting, which has limited effectiveness. A test that has become more prevelant is the "societal test", which considers aggregate benefits and costs, but not their distribution. DSM programs (certainly the utility planning component) are supported by all the ratepayers, yet the benefits accrue to the few participants who receive lower utility bills. An example of a DSM program with redistributive effects is the so-called "Golden Carrot" program, which is a contest where utilities have raised about $\$ 30$ million as a prize to the manufacturer of a new energy efficient refrigerator. The inequity arises because the cost is borne by utility customers and the benefits are captured by a firm and perhaps by a few customers who buy a new efficient refrigerator at a subsidized price. The goal of this program is to enhance energy efficiency not economic efficiency. If a refrigerator could be developed to have lower life cycle costs by having lower maintenance costs or a longer lifetime, economic efficiency would be increased but the goal of the program would not be met.

\section{MARKET BARRIERS}

In addition to the policy goals, a second area of disagreement between the economics and conservation paradigms is the methodology used to analyze the behavior of energy markets. The disagreement is with the analytical foundations of energy policy. ${ }^{4}$ The economics model asserts that the failure of private market to allocate resources efficiently and equitably is the appropriate basis for policy analysis. The conservation model asserts that market barriers impede the effectiveness of private markets in achieving energy efficiency. An economics perspective implies that the conservation model may lead to a misallocation of resources because neither market barriers nor energy efficiency are appropriate for policy analysis.

A review of the conservation literature suggests that a fundamental proposition of conservation research is that numerous opportunities currently exist for cost-effective investments in energy efficiency, but are not undertaken because of market barriers. Conservation measures are investments because they involve an initial commitment of funds with the expectation of future cost savings. The conservation view is that market barriers discourage investments in energy efficiency. The policy implication is that energy efficiency

${ }^{3} \mathrm{An}$ allocation of resources is considered Pareto optimal if no redistribution of resources can make someone better off without making someone else worse off.

4 My previous discussion of market barriers (Sutharland 1991) considered most of the barriers contained a literature review by Hirst and Brown (1990) and contrasted them with an economic perspective of market failures. This discussion of market barriers considers only a sample of such barriers and relates them to a larger conservation verses economics framework. 
can be encouraged by reducing these market barriers.

Analyses based on market barriers are not likely to yield useful policy prescriptions to the extent that market barriers are not indicative of a misallocation of resources. The contention here is that the alleged market barriers that discourage energy efficiency are not consistent with the economic analysis that defines the failure of private markets to behave efficiently. As developed below, the alleged market barriers are subject to three criticisms. First, these market barriers are not specifically related to energy investments. Instead, they are assertions about investment behavior in general that appear are applied to energy efficiency. Second the alleged market barriers are not consistent with conventional investment analysis as reflected in textbooks in investment, finance and portfolio analysis. Thirdly, the alleged market barriers do not imply that resources are being used inefficiently, including investments in energy-related technologies. Market barriers are ad hoc explanations not based on existing scientific analysis of market behavior. Some proposed market barriers are simply benign characteristics of well functioning markets. The implication is that energy policies, including the National Energy Strategy of the DOE, need not be concerned with the alleged market barriers, but only with the failure of private markets to allocate resources efficiently.

\section{Attitudes Toward Energy Efficiency}

In their discussion of "... barriers to the efficient use of energy", Hirst and Brown (1990) present an excellent overview of the conservation perspective of market barriers and how they retard efficiency. According the Hirst and Brown (p. 274), "Americans, during most of the 1980s, lost interest in saving energy as fuel prices dropped and supplies were plentiful." The apparent market barrier is the reduction in energy prices and the consequence is that a reduction in energy consumption was discouraged. This market barrier provides an insight into the thinking of conservation researchers. The increased use of energy at lower prices is not indicative of a malfunctioning market, rather it is a simple application of the law of demand. After more than two decades of analysis, how can conservationists fail to recognize that the increased use of good at reduced prices is part of the process by which resources are allocated efficiently? A partial explanation is that many conservation researchers come from an engineering or physical sciences background and their economic analyses are primarily present value and life cycle calculations.

A second explanation of reduced energy prices as a market barrier is that the goal of conservationists is to reduce energy consumption, not to allocate resources efficiently. Lower energy prices are indeed a market barrier to energy efficiency investments, but not to economically efficient investments. With a decrease in energy prices, economic efficiency is enhanced by substituting the lower cost input for relatively higher cost inputs. Such a substitution contributes to a least cost use of all resources. Energy efficiency is discouraged by lower energy prices, but energy efficiency is not consistent with economic efficiency. The alleged market barrier of "attitudes towards energy efficiency" is a market barrier, but it does not imply that private markets are functioning inefficiently. The apparent goals of least cost and cost-effectiveness are a constraint imposed on conservationists, not the objective 
of their recommendations. The reduced cost of energy is a barrier to energy efficiency, but not to the least cost use of energy.

\section{Limited Access to Capital}

If economic efficiency is the accepted policy objective, the contention must be that the capital market artificially discriminates against energy related investments that are economically efficient. Financial capital moves nationally and internationally in seconds to seek out the most favorable investment opportunities. This market is highly competitive; it is effective in discovering good investments and in discriminating against bad investments. Investments that enhance economic efficiency are likely to be supported by the capital market. Capital markets do not make each investment decision correctly. However, they do not artificially and consistently discriminate against economically efficient investments that are energy related.

The explicit contention of Hirst and Brown is that the capital market discriminates against investments in energy efficiency. This assertion is probably correct. Capital markets have no incentive to finance investments, where the goal is to reduce energy consumption, or, merely to substitute one input for another. Capital markets are not motivated to finance investments that enhance energy efficiency, but they will certainly support investments that are economically efficient.

Alfred Kahn (1992) objects to the view that consumers are unable or unwilling to finance debt for energy efficiency investments by pointing out that consumers have considerable debt: a half a trillion dollar debt in home mortgages, almost $\$ 300$ billion in installment debt for automobiles and over $\$ 700$ billion in total consumer installment debt. Homes and automobiles are major users of energy and other energy users could be financed by other installment debt. The capital market certainly channels billions of dollars into the consumer sector in areas where energy is used. The contention that this market is economically inefficient by discriminating artificially against energy related goods and services appears hard to justify.

\section{The Occupancy Hypothesis}

This hypothesis is that energy efficiency investments that would be undertaken in owner occupied buildings may not be undertaken in renter occupied buildings. There are two issues: one is the validity of the hypothesis. A renter occupied buildings typically contain fewer conservation features than owner occupied buildings? My analysis of conservation measures in commercial buildings (Sutherland, 1991) concludes that typically occupancy does not affect the level of energy efficiency investments. The analysis included regression estimates and reference to a large nationwide survey by the Energy Information Administration.

The second aspect of this hypothesis is its conceptual soundness. The occupancy hypothesis is similar to other alleged market barriers, first by not being specifically related to investments in energy efficiency. If renter occupancy discourages energy related 
investments it must discourage other investments, such as in improved operation and maintenance, as well. There exists no causal relationship between renters and energy investments. Secondly, the hypothesis is inconsistent with conventional investments analysis as summarized at the textbook level. The conservation literature has merely asserted the occupancy hypothesis to be valid and has not offered a theoretical development. Conceptual support for this hypothesis could be developed on the basis of transactions costs. Consider an owner occupied building where the owner is willing to undertake an investment to reduce energy costs. Now imagine the same building that is renter occupied. If an energy saving investment is cost-effective, the owner must renegotiate the lease with the renter so that each can share the benefits of a reduced $\epsilon$ srgy cost. This renegotiation is a transactions cost not present in owner occupied buildings that could discourage investment. If the dollar savings were large, the transactions cost would not impair the investment. However, if the dollar savings were small, the transactions cost would discourage the investment. In the latter case, energy efficient investments may not be undertaken in renter occupied buildings, but this behavior is consistent in the efficient use of resources.

These transactions costs would not characterize master metered buildings. In this case the building owner makes the investment and receives the rewards. ${ }^{5}$ New buildings being constructed and not yet rented would not have such a transactions cost. A simple elaboration of the occupancy hypothesis suggests some clarifications that would result in a sharper empirical analysis. The occupancy hypotheses is not objectionable per se, but it should be developed in terms of transactions costs and tested accordingly. Furthermore, the potential for gains in economic efficiency depends on whether observed transactions costs are unnecessarily high.

Perceived Risk of Energy-Efficiency Investments

Conservation investments are risky and this risk is alleged to be a barrier that discourages investment. The actual rate of return on conservation investments varies widely about its expected value and this variation is a measure of risk. There is an enormous volume of technical literature on the importance of risk in investment decisions. One of the basic results of this literature is that a large share of risk can be diversified away in efficient portfolios of risky assets. In those cases where risk is reduced or eliminated, it will not impair investment. If an investor holds a portfolio of such risky assets, much of the risk will vanish and :isk of the investment becomes irrelevant for investment purposes. (One of the major functions of a capital market is to raise capital at the least cost and this is accomplished by investors diversifying away risk in total portfolios.) The implication is that if risk can be diversified away, it does not discourage investment. This alleged market barrier follows the pattern of the other market barriers. Modern investment analysis does not support the view that the alleged barrier discourages investment. Secondly, the alleged

${ }^{5}$ In master metered buildings the marginal cost of energy to the occupant is zero, which should result in a large and inefficient use of energy. The building owner has an even larger incentive to invest in energy savings in this case. 
barrier is not uniquely related to energy, but is a general hypothesis about investment behavior. Thirdly, to the extent that not all risk can be diversified away, it is a normal business risk, and does not result in a misallocation of resource (Sutherland, 1991).

If risk cannot be diversified away, an investor in an efficient market will require a higher rate of return to undertake the investment. Corporate investments are reflected in the price of their common stocks, where most risk is diversified away in large stock portfolios. High income households may be able to reduce the risk of many investments by holding diversified portfolios of earning assets. Low income households probably have small investment portfolios and are unable to reduce the risk of major investments. Low income households tend to require higher discount rates than high income households or corporations for investments with a given level of risk.

Conservation researchers may look at the risk of conservation investments and suggest policies to reduce this risk. A preferable policy may be to shift the risk to those who can bear it at least cost. For instance, corporations should be used to implement and finance energy efficiency strategies rather than households, because the required rate of return is lower. If an investment is feasible for a corporation but unfeasible for an individual, policies that create incentives for corporations may enhance economic efficiency. A second implication of the riskiness of conservation investments is that energy efficiency standards are a regressive tax. Low income households bear the risk of the investment, high income households can reduce this risk. Consequently, the cost of risky conservation measures bears most heavily on those least able to afford it. Orie issue here is equity, that is whether low income households should be made worse off as a result of standards. The second issue is economic efficiency. If the required discount rate for low income households is much higher than for high income households or corporations, then efficiency standards that reflect a single discount rate can be economically efficient for low income households. This undesirable effect argues for policies that use market processes rather than rigid standards or controls.

\section{Uncertainty About Future Fuel Prices}

The future of fuel prices is highly uncertain and forecasts have often been unreliable. According to Hirst and Brown (1990, p. 7) "Uncertainty about fuel prices is a barrier to investment in both manufacture and purchase of energy-efficiency systems." This alleged barrier follows the pattern that it applies to investment behavior in general and not specifically to energy related investments. From one perspective, the alleged barrier is also inconsistent with conventional investment analysis. Microeconomic theory asserts that a risk averse firm will shy away from inputs whose future price is risky. A firm that views future fuel prices as risky will tend to substitute capital or labor for fuel. The effect of fuel price risks is to encourage energy saving investments and such behavior is economically efficient. Future fuel prices are indeed uncertain, but this risk should have the opposite effect than alleged. As discussed below, uncertain fuel prices may have the effect of delaying investment decisions. 


\section{First Costs}

Another alleged market barrier to energy saving investments is that initial costs are too high. The initial cost must be weighed against the present value of energy cost savings. This market barrier could be restated to assert that the future cost savings are too low. This so-called market barrier has no basis in the conventional analysis of investment behavior. If the initial cost of an investment is too high relative to the payoff, the investment is simply not cost effective.

This brief review of some market barriers alleged by conservationists again suggests the conclusions that such barriers are not consistent with standard economic analysis of investment, nor do they impair the efficiency with which markets allocate resources. These conclusions need some qualifications. First, two of the alleged market barriers - uncertain future prices and initial fixed costs - may account for a delayed response in investment to profitable investment opportunities. Two other market barriers - fuel price distortions and regulatory distortions - are also market failures.

Two market barriers have been subject to a significant amount of economic analysis. The barrier of high fixed costs could also be construed as an investment that is irreversible. Energy related investments are typically irreversible. Investments in physical capital tend to be irreversible, regardless of whether they use energy. I have previously described this concept as illiquidity and suggested that it partially explains high discount rates for energy efficiency, particularly by low income households. Also, uncertain future fuel prices suggests that investments in energy using capital will be encouraged to be energy efficient. However, uncertain future product or fuel prices may retard the rate of investment, including investment in energy saving capital.

Pindyck (1991) has summarized a large volume of economics literature on irreversible investment decisions with product price uncertainty. Under these assumptions, a rational, profit maximizing firm will delay making apparently efficient investments and acquire future information about product prices. In the neoclassical model, investment is asserted to occur when the expected rate of return exceeds the cost of capital. In the examples provided by Pindyck, a firm may wait to invest and obtain a higher net present value than investing today. Hassett and Metcalf (1992) allow for fuel price uncertainty in a model with irreversible investments and conclude that the rquired discount rate for energy efficiency investments may be increased by a factor of four. Under realistic conditions, conventional economic analysis concludes that profitable investment opportunities will not be undertaken immediately, but will be distributed over a period of time. Irreversibility and uncertainty delay the rate of economically efficient investment; however, resources are being allocated efficiently over time. Investment lags are not a market failure; they are not a source of inefficiency; and they are not an appropriate basis for government policies.

The rate of adoption of new energy related technologies may also be analyzed using a diffusion theory framework. Diffusion analysis accounts for the rate of adoption of new, economically superior technologies to occur gradually over time and generally to follow the 
"S" shaped or sigmoid curve (Jaffee and Stavins, 1991). Diffusion analyses have been used to explain the rate of adoption of optical scanners, hybrid corn seed, steel furnaces and numerous other innovations. If the alleged market barriers were developed within a diffusion theory framework, they could achieve a measure of credibility.

\section{MARKET FAILURES}

\section{Fuel Price Distortions}

The market price of several fuels does not reflect the true social costs and in particular neglects environmental costs. With energy being underpriced in the market, conservation investments are less profitable and are therefore discouraged. Conservationists and economists generally agree that energy is not priced efficiently and the result is economic inefficiency and a bias against energy efficiency. The fuels of most concern are coal, petroleum and uranium.

At the retail price level, both electricity and natural gas are priced differently from their marginal private costs as well as their marginal social costs. As a result of regulation, retail prices reflects the average value of capital, which depreciates over time, rather than marginal costs. Nichols (1992a) expands on this point and asserts that inefficient pricing as a result of regulation and environmental costs is the main market failure in regulated energy markets.

Inefficient pricing due to regulation has long been recognized to characterize electricity, but it characterizes gas as well. The retail price of gas in the residential and commercial sectors tends to be higher in the summer and lower in the winter than would be suggested by marginal cost pricing. The Energy Information Administration (EIA, August, 1990, p. 10) reports that during 1989 and 1990, the residential price of gas is more than four times the wellhead price during the summer months, but less than three times the wellhead price during the winter months. If the city gate price were used as the market price instead of the wellhead price, a similar pattern emerges. Artificially low gas prices during the summer months discourage the commercialization and use of gas cooling technologies. The Gas Research Institute and the DOE each have R\&D programs designed to promote gas cooling. The widespread adoption of this technology would make an important economic contribution to the gas and electric supply industries by leveling out the seasonal demand for each fuel. However, inefficient pricing due to regulation discourages the use of this technology. The DOE and numerous states have conservation policies to promote the reduction of the demand for gas during the winter months. With the price of gas at less than marginal costs during these months, conservation efforts are discouraged. The failure of the retail price of gas to reflect seasonal variations in market prices results in inefficiencies in the use of gas, the use of substitute fuels and in the choices of fuel using technologies.

\section{Transactions Costs}

Some conservation researchers now recognize the limitations of justifying policies on 
the basis of market barriers and the necessity of identifying market failures. The LBL researchers now argue that a serious market failure characterizing energy related investments is high transactions costs: "The prima facie case for transactions cost problems in energy related decisions is particularly strong..." (Sanstad, et. al., 1992, p. 10). The early literature on market barriers, such as Blumstein, et. al. (1980) and Hirst et. al (1982) does not mention transactions costs. The more recent literature reviews of market barriers by Hirst and Brown (1990) and Carlsmith et. al. (1990) does not include transactions costs as a market barrier. This literature has always emphasized the lack of information - or information costs - as a market barrier and information costs are a component of transactions costs. However, the papers by Sanstad et. al., and by McMahon (1992), identify no transactions costs, other than information costs, nor do they present evidence that such costs may be significant. These papers are an attempt to justify tie conservation paradigm in terms of market failure; however, they merely assert that such a market failure exists and it is important.

In contrast to the assertion of LBL, the transactions costs associated with energy efficiency are in most cases insignificant and do not justify efficiency standards or DSM programs. Energy efficiency is one characteristic of an energy using device. The transactions cost associated with energy efficiency is the incremental cost due to purchasing the energy efficiency component of the good. For instance, the transactions cost of purchasing an automobile is certainly positive, but the transactions cost of purchasing a fuel efficient automobile is the incremental cost of purchasing one that is fuel efficient. Almost all the transactions costs required to purchase an automobile are invariant to fuel efficiency. The incremental transactions cost of fuel efficiency is approximately zero. Consumer purchases of energy using appliances should also have negligible incremental transactions costs of purchasing energy efficiency. Appliance labelling reduces information costs. Such labelling does not provide perfect information and additional search costs may be necessary for the consumer to make an optimum choice. This search cost could be construed as a transactions cost of energy efficiency. Energy efficiency is not unique, or always the most important cost of a technology. A similar information cost is required if the consumer is to understand the durability and economic lifetime of an energy using appliance. The incremental transactions costs of purchasing energy efficiency in appliances is probably limited to the information costs that have been long recognized. No additional costs have been identified by the LBL researchers, nor are they apparent.

In addition to the residential and transportation sectors, a significant amount of energy is used in the industrial sector and in commercial buildings. The economic model of investment implies that capital investments in energy using technologies are made with the same analysis as other investments. For instance, the purchase of an economically efficient HVAC system for a commercial building requires information about the economic characteristics of alternative HVAC systems. However, no incremental transactions cost should characterize an energy efficient purchase. Similarly, in the industrial sector capital investments are made on the basis of engineering and economic assessments of alternatives. There appears to be no basis for asserting that the energy efficiency component of such 
investments have high transactions costs.

The transactions cost of purchasing energy efficiency in an energy using device is not unique nor particularly high. Rather, the clear impression is that conservationist: advocate reducing energy consumption and then use the transactions cost argument to justify their policy positions in terms of a market failure. Information is not perfect and supplied to everyone free of charge. And transactions costs are not zero. However, these market characteristics do not provide a generalized market failure that justifies conservation policies. If a large sample of markets were randomly selected and surveyed for imperfections due to transactions costs, it is doubtful that energy efficiency transactions would be selected. Labor markets, particularly involving low skilled labor, may be a more serious concern.

A major focus of conservation policy has become utility DSM programs, or, integrated resource planning (IRP), which considers both demand and supply options to meet energy service demand. The conservationists' advocacy of DSM programs reflects the contrasting paradigms between economists and conservationists and particularly the conservationists' emphasis on energy efficiency and reducing energy consumption. Gas and electric utilities may have a bias towards producing too much energy. Inadequate incentives exist for satisfying the demand for energy services by means that use less energy. Integrated resource planning and DSM have developed as a response to this bias in the energy supply market. ${ }^{6}$

The failures or barriers that rationalize these DSM programs are that utility regulation imparts a bias that encourages utilities to meet load growth by building power plants at an allowable rate of return rather than attempting to reduce the demand for energy. A second bias in this system is that energy is not competitively priced. The prices of electricity and natural gas do not reflect their environmental costs. The marginal costs can vary seasonally and daily, and prices to customers do not typically reflect these variations in marginal costs. The conservation paradigm approaches the symptom of these inefficiencies by arguing that the appropriate goal is to increase energy efficiency via DSM programs.

The economics model focuses on the causes of the inefficiency, which are market failures. One market failure, the lack of efficient pricing for both regulatory and environmental reasons, could be corrected by more efficient pricing. If energy is significantly underpriced, the success of DSM programs appears severely constrained. If energy is priced competitively, then the need for DSM programs is less clear. From an economics perspective, energy efficiency is not the problem and utility DSM programs not the obvious solution.

${ }^{6}$ The concern here is with the DSM programs designed to reduce overall load demand rather than to redistribute it. 
A second inefficiency is the regulatory failure in the form of a regulatory compact that produces the bias towards building by providing an allowable rate of return to investments prudently made. Energy inefficient investments are the symptom of this problem, they are not a fundamental causal variable. The objective of forcing or motivating utilities to make energy efficient investments seems ill-conceived. A preferred alternative is to recognize that the system of cost-plus regulation is inherently inefficient and to design programs that do not rely on regulation. Conservationists tell us that energy services can be supplied at a much lower cost through conservation programs than through capital investments to supply energy. If this assertion is true, the efficient pricing of energy should contribute to the success of these conservation efforts. If individual consumers have higher discount rates than we believe socially desirable, efficient pricing of energy may not be sufficient to encourage an optimum level of conservation. Energy service companies (ESCOs) could meet the demand for energy services and compete effectively if indeed conservation measures are cost effective. This proposed solution reflects the view that the failure is in the regulatory process. The conservationist advocacy of utility DSM programs reflects the view that energy efficiency is the appropriat; goal rather than economic efficiency.

\section{Energy Policies}

Because of its focus on energy efficiency, the conservation paradigm is not applicable to broad spectrum of energy policy issues, but is limited to at most the range of issues where energy efficiency and economic efficiency coincide. This range is indicated by the intersection of the economic and energy efficiency sets in Figure 1. The conservation paradigm cannot address policy issues where economic efficiency may be improved by fuel switching or by increasing energy use. To illustrate this point, five important energy policy issues are discussed briefly. The implication is that policy issues can be addressed from the perspective of market failures or imperfections and not from the perspective of energy efficiency and market barriers.

(1) Electric utilities have historically been granted franchise monopolies because of economics of scale in the generation and distribution markets. This natural monopoly is a market failure. The current view is that natural monopoly characterizes the distribution of electricity not its generation. If the generation maiket is not characterized by an inherent market failure (natural monopoly), encouraging the development of a non-utility generation market should contribute to economic efficiency and a lower cost of producing electricity.

(2) The Department of Energy has a multibillion dollar budget used for R\&D. The policy objective is to allocate this budget to make the most efficient use of resources. Three specific policy goals are: environmental quality, energy security and economic efficiency. The private sector has insufficient incentives to invest at an efficient level to achieve the above three policy objectives. The market failures are: externalities, public goods and the lack of aggregate insurance markets (Sutherland, 1989). DOE investments can be designed to reflect these market failures and thereby to produce net benefits to the public. 
(3) Prior to the mid 1980s, natural gas pipeline companies purchased gas from producers, transported the gas and sold it to distribution companies and to other end users. Gas was purchased and sold under long term contracts, typically with relatively fixed prices. A characteristic of this market was that the pipeline was the single buyer of gas and then a single seller of gas. This market failure was remedied by FERC Order 436, that encouraged pipelines to become common carriers. The gas supply market experienced a rapid transformation where a large number of buyers and sellers could conduct business. A spot market and a futures market developed and reflects competitive market prices. The improved economic efficiency in this market resulted from wellhead price decontrols, but also from improved access to transportation. The improved economic efficiency in this market could have resulted in increased gas use and in a substitution of gas for oil. The effect on energy efficiency is ambiguous and irrelevant.

(4) Oil pipelines are common carriers, but their rates are regulated by the FERC and are inflexible. The rationale for rate regulation is that product and crude markets are characterized by a small number of buyers and sellers, which permits monopoly power. Analysis by the Department of Justice (Untiet, 1987) indicates that most product markets have enough buyers and sellers to justify deregulation. Again, the policy recommendation depends on the competitiveness of the market, in this case, on the number of market participants.

(5) A key component of energy strategy at the national and utility level is to maintain a diversified set of future options. For instance, electiicity can be generated from several sources such as coal, natural gas, nuclear, wind and hydro, to list just a few. If we consider various fuel substitution possibilities, such as wind for coal or gas for nuclear, measuring energy efficiency as Btu input relative to electricity generation becomes meaningless. Issues that involve fuel substitution cannot appropriately be analyzed by a paradigm focusing on energy efficiency.

The common theme of these five issues is that appropriate policy depends on identifying market failures and designing policies that improve economic efficiency. In each of the above examples, market barriers and energy efficiency are not relevant considerations.

\section{THE ECONOMICS AND CONSERVATION PARADIGMS}

The economics and conservation paradigms have thus far been defined in terms of policy goals (economic or energy efficiency), and impediments to investment (market failures or barriers). In this section, we note first that the direction of analysis is different in these two models. Second, the conservation paradigm is characterized by engineering analyses of efficient technology choice, rather than by ideal market behavior.

Direction of Analysis

The economics paradigm begins with an analysis of the efficiency with which a market is functioning. In each of the above issues, the direction of analysis is from an 
identified market failure to a policy that enhances economic efficiency. When a market failure is identified, a government policy may be proposed to reduce the failure.

The conservation faradigm begins with the policy objective of energy efficiency and then explains the failure of markets to purchase these technologies in terms of market barriers. The analysis togins with a data search to locate the large energy users and thereby to identify opportunities for improved energy efficiency. Energy consumption is the target of the analysis, rather than sources of market failures. After selecting the entities of high energy intensity, technologies or various conservation measures are proposed to improve energy efficiency. Present value calculations are then used to show that the new technologies are cost effective. From an engineering perspective and life cycle cost analysis, such technologies are indeed superior products. When markets are observed to refuse these apparently superior technologies, arguments based on market barriers are invoked to explain the failure of the private sector to make energy efficiency investments. The recommended policy solution is typically to mandate energy efficiency in the form of standards, regulations, or DSM programs.

This interpretation of conservation policy analysis accounts for the large number of alleged market barriers and the inconsistency between these alleged market barriers and recognized market failures. The market barriers were proposed to justify conservation policies and to explain the refusal of the markets to adopt these obviously superior products. For instance, conservation advocates observe that a new energy efficient technology may be a risky investment and risk is therefore alleged to be a barrier to investment. If the scientific literature on investment behavior under risk had been reviewed in terms of barriers or failures, some market failures could be identified. However, such an analysis would not have singled out energy related investments as a symptom of inefficiency. The conservationists also argue that energy efficiency investments have limited access to capital. Research on capital markets has concluded that the markets are basically efficient. However, capital markets certainly make mistakes. A review of the technical literature on capital markets reveals no systematic bias against efficient investments that are energy related. Again, had the literature been reviewed first, the conclusion about a bias against energy efficiency never would have been reached. These two examples support the general contention that alleged market barriers have been constructed after the fact to rationalize conservation policy recommendations. An initial analysis of energy markets in terms of market failures would not have yielded the conservationists conclusions or policy recommendations.

\section{Technologies and Markets}

Economists and conservation advocates may appear to have common ground in that economic and energy efficiency imply that goods and services are produced with least cost. Conservationists have accepted the goal that energy efficiency should be attained at least cost. Economists and conservationists could therefore agree that a particular allocation of resources is both economically efficient and energy efficient. These policies are defined graphically by the intersection of the energy and economic efficiency sets in Figure 1. 
However, the economics concept of efficiency emphasizes market behavior and equating costs and benefits at the margin. Conservationists use an engineering approach that focuses on efficiency as a least cost use of technologies.

As an example of this engineering approach, the report by Carlsmith et. al. (1990) considers three alternative projections of U.S. energy use from 1988 through the year 2010. One energy consumption path assumes that energy efficiencies are frozen at 1988 levels. The second scenario, "where we are headed", assumes that present trends towards energy efficiency are continued, but no new programs are initiated. In this scenario, market forces will improve energy efficiency by 12 percent by the year 2000 over the frozen efficiency scenario. An additional 13 percent improvement in energy efficiency is possible in the costeffective efficiencies scenario, but will not be realized without government efforts to reduce barriers to energy efficiency.

This incremental 13 percent improvement in energy efficiency is bá ed on engineering calculations. At issue is whether this energy efficiency represents an economically efficient use of resources. The conservation analysis does not address this question explicitly, but economic efficiency is implied because the scenario is cost-effective. However, there are compelling reasons why an economically efficient market would select different technologies than engineers estimate to be cost-effective. First, technologies that are cost-effective by engineering estimates may not reflect consumer preferences that can vary temporally and regionally and reflect frequency of use. Second, consumers have widely varying discount rates that tend to be income related. Consumers with high discount rates may prefer riskless and liquid cash to energy efficiency investments that engineers have asserted to be cost-effective. Thirdly, the natural rate of diffusion may be gradual and it may occur over a large number of years. The irreversibility of capital investments and the benefits of waiting to identify permanent price paths suggest that economically efficient investments will not immediately respond to market opportunities. Government efforts to accelerate the rate of diffusion over an efficient market process, sufficient to achieve the "cost-effective" conservation scenario, may have dollar costs that exceed dollar benefits. For these reasons, the cost-effective energy efficiency scenario described by Carlsmith may not correspond to economic efficiency.

In a recent study, Nichols (1992) reviewed a large number of utility DSM programs plus numerous additional conservation studies. A major conclusion is that conservation programs - even highly successful ones - come up short of their initial engineering estimates in terms of energy saved. The implication is that engineering estimates of cost-effective energy savings exagerate the energy savings resulting from efficient market responses.

In the conservation model, the life cycle costs of existing energy using technologies are compared to the same costs of energy efficient technologies to conclude that the efficient technologies would save enormous resources. This model includes the development and production costs of new technologies but not their diffusion costs. In a competitive and efficient market the rate of diffusion of a new and superior product is not instantaneous. 
The rate of diffusion of economically efficient and energy efficient technologies can be gradual because of market failures and market barriers (Jaffee and Stavins, 1991). The market barriers discussed above and in Sutherland (1991) indicate that most of the market barriers do not affect investment decisions and therefore do not affect the rate of diffusion. To the extent that other market barriers lengthen the diffusion process but are not market failures, they do not justify Government policies to encourage adoption. Market failures are however an important concern. If the market price of energy understates its true social cost, by not reflecting environmental costs, then efficient technologies will be adopted more slowly. A policy of efficient energy pricing would accelerate the diffusion process and improve economic efficiency.

\section{Summary}

The conservation paradigm is described here as reflecting the policy goal of energy efficiency, the investment model that market barriers inhibit energy efficiency investments and the emphasis of engineering estimates of market efficiency. In contrast, the economics paradigm emphasis economic efficiency and equity, market failures or market imperfections as impediments to achieving economic efficiency and the behavior of markets to make efficient choices. Market barriers may discourage investments in energy efficiency, but this is irrelevant for policy purposes where energy efficiency differs from economic efficiency. Where market barriers discourage economically efficient investments, they are of dubious significance for policy purposes unless they are market failures. The market barriers alleged in the conservation literature typically do not coincide with market failures. In a competitive and efficient market economy, investments judged efficient by engineering and present value calculations will not instaneously achieve a market share of 100 percent. Barriers that delay diffusion are not necessarily appropriate for Government policy.

An economic analysis of markets focusing on market failures is the appropriate analytical framework to analyze energy issues. The appropriate issue is the economically efficient uses of resources and, in particular, energy resources. An analysis based on market barriers is limited to address a specific question, namely the rate of adoption of energy efficiency technologies. The appropriate framework to address this question is not merely to assert that market barriers exist. Instead, the analysis should consider the existing scientific literature on diffusion theory and irreversible investments that seeks to explain the rate of investment, relative to that of the neoclassical model. Energy technologies are merely a special case of a new technology. Next, conservationists need to show that accellerating the rate of diffusion enhances economic welfare.

The economics model confronts conservationsits with a major intellectual challenge. If they accept the goals of economic efficiency and equity, many of their favorate policy programs, such as appliance standards and integrated resource planning, would be theatened with revision or abolition. If conservationists continue to reject the economics model, they will continue to be vulnerable to the charge of advocating policies that misallocate resources and contribute to income inequity. Conservation researchers appear to be highly effective 
at communicating between themselves, but much less effective at selling their message to outsiders. The conservation community needs to focus, not on energy efficiency per se, but on the economically efficient use of energy resources and to do so using a widely accepted and analytically sound framework. The first priority should be to eliminate fuel price distortions. The result will probably be policy recommendations that are economically efficient, are more widely accepted, and probably result in a decrease in energy use as well as the substitution of clean and domestically available fuels for other fuels.

\section{References}

Andersen, Hans C. , "The Emperor's New Clothes" in Clifton Fadimon (ed.) The World Treasury of Children's Literature, Little, Brown and Co., Boston, 1984, pp. 457-462.

Blumstein, Carl, Betsy Kreig, Lee Schipper and Carl York, "Overcomming Sociai and Institutional Barriers To Energy Conservation"' Energy, Vol. 5, April, 1980, pp. 355-371.

Carlsmith, Roger S. and W. Chandler, J. McMahon and D. Santini, Energy Efficiency: How Far Can We Go?, Oak Ridge National Laboratory, ORNL/TM-1141, January, 1990.

Energy Information Administration, Natural Gas Monthly, U.S. Department of Energy, Washington, DC, DOE/EIA-0130(90/08), August, 1990.

Hasset, Kevin A. and Gilbert E. Metcalf, "Energy Conservation Investment: Do Consumers Discount the Future Correctly?" unpublished manuscript, Columbia University, Graduate School of business, 1992.

Hirst, Eric and Marilyn Brown, "Closing the Efficiency Gap: Barriers to the Efficient Use of Energy", Resources, Conservation and Recycling, Vol. 3. 1990, pp. 267-281.

Hirst, Eric, William Fulkerson, Roger Carlsmith and Thomas Wilbanks, "I,proving Energy Efficiency", Energy Policy, June, 1982, pp. 131-142.

Jaffe, Adam and Robert Stavins, "The Energy Paradox and the Diffusion of Conservation Technology", The National Bureau of Economic Research, Conference on Economics of the Environment, Cambridge, Mass. December 13-14, 1991.

Kahn, Alfred E. "Least Cost Planning Generally and DSM in Particular", Energy and Resources, Vol. 14, 1992, pp. 177-185.

McMahon, James E. "Imperfect Markets and Energy Efficiency", unpublished manuscript, 
Lawrence Berkeley Laboratory, Energy Analysis Program, Berkeley Ca., July 1992.

Nichols, Albert "How Well Do Market Failures Support the Need For Demand Side Management?", National Economic Research Associates, Cambridge, Mass., DRAFT, July, 1992.

Nichols, Albert, "How Much Energy Do DSM Programs Save: Engineering Estimates and Free Riders," National Economic Research Associates, Cambridge, Mass., DRAFT, July, 1992.

Pindyck, Robert S. "Irreversibility, Uncertainty, and Investment", Journal of Ecnomic Iiterature, Vol. XXIX, September, 1991, pp. 1110-1148.

Sanstad, Alan H., Jonathan G. Koomey and Mark Levine, "On the Economic Analysis of Problems in Energy Efficiency: Market Bar iers, Market Failures, and Policy Implications" unpublished manuscript, Lawrence Berkeley Laboratory, Berkeley, CA., July 1992.

Sutherland, Ronald J., "An Analysis of the U.S.Department of Energy's Civilian R\&D Budget", The Energy Journal, Vol. 10, No. 1, May, 1989, pp. 35-54.

Sutherland, Ronald J., "An Analysis of Conservation Features in Commercial Buildings", Energy Systems and Policy, Vol. 13, 1990, pp. 153-166.

Sutherland, Ronald J., "Market Barriers to Energy-Efficiency Investments," The Energy Journal, Vol. 12, No. 3, 1991, pp. 15-34.

U.S. Department of Energy, National Energy Strategy, U.S Department of Energy, Washingtori, .DC, February, 1991.

Untiet, Charles, "The Economics of Oil Pipeline Deregulation: A Review and Extension of the DOJ Report", US Department of Justice, EAG-87-3, May 22, 1987. 

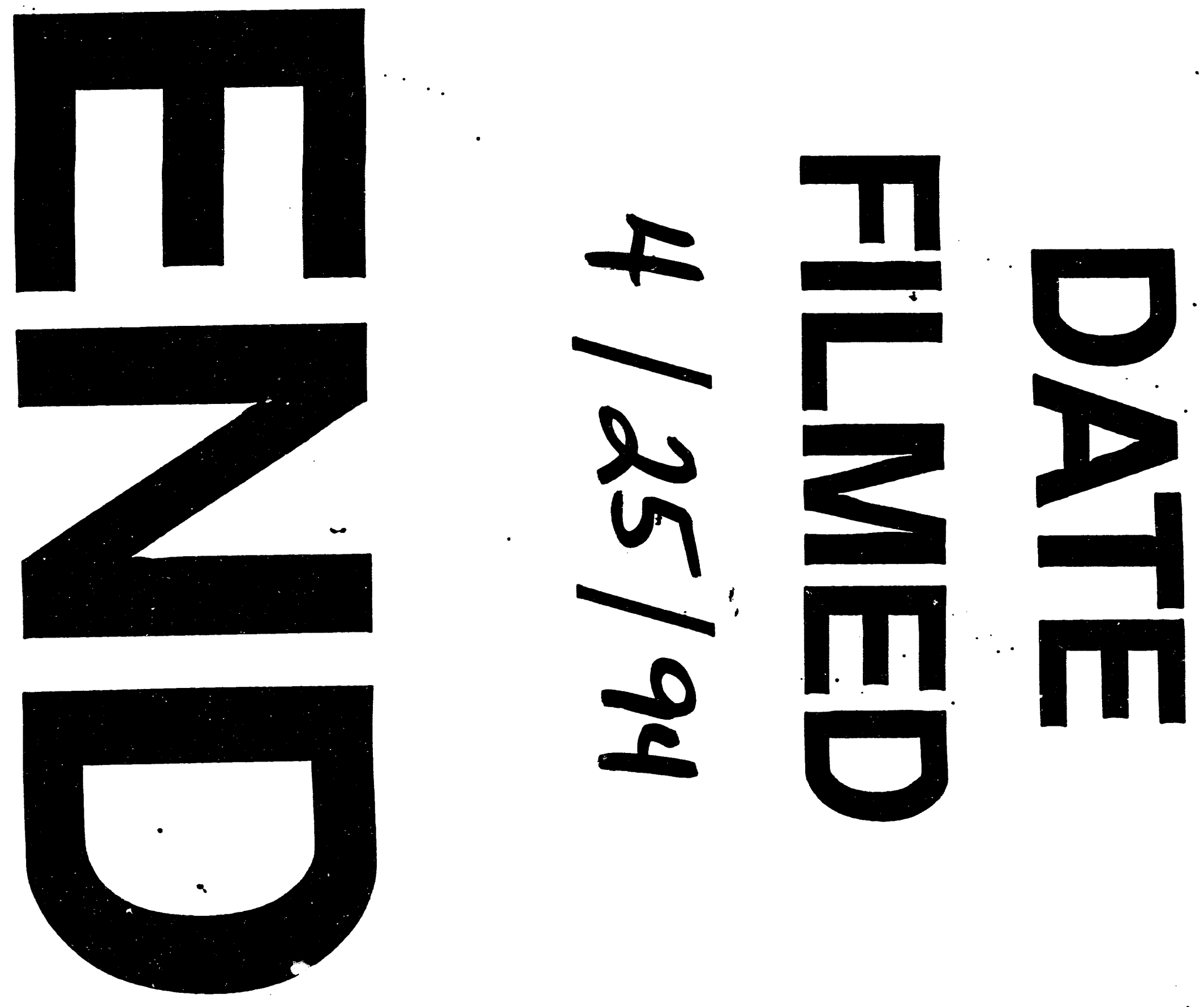
